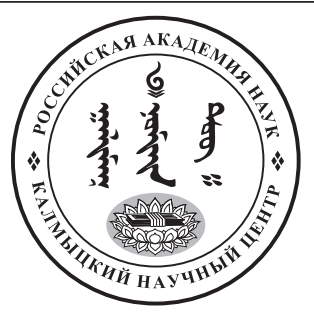

Published in the Russian Federation

Oriental Studies (Previous Name: Bulletin of the Kalmyk Institute

for Humanities of the Russian Academy of Sciences)

Has been issued as a journal since 2008

ISSN: 2619-0990; E-ISSN: 2619-1008

Vol. 13, Is. 1, pp. 75-92, 2019

DOI: $10.22162 / 2619-0990-2020-47-1-75-92$

Journal homepage: https://kigiran.elpub.ru

УДК $397+398$

\title{
Образ лисицы в культуре хакасов (конец XIX - середина XX в.)
}

\section{Венарий Алексеевич Бурнаков ${ }^{1}$}

${ }^{1}$ Институт археологии и этнографии СО РАН (д. 17, пр. Лаврентьева, 63090 Новосибирск, Российская Федерация)

кандидат исторических наук, старший научный сотрудник

iD 0000-0001-9636-3081.E-mail: venariy@ngs.ru

(C) КалмНЦ РАН, 2020

(C) Бурнаков В. А., 2020

Аннотация. Введение. Статья посвящена анализу одного из ключевых зоологических образов - лисицы в традиционном быту, социо-нормативной и обрядовой практике хакасов. Целью работы является характеристика образа лисицы в культуре указанного народа. Исходя из этого, были поставлены такие задачи, как: выявление роли лисицы и ее образа в быту и практической деятельности; определение значения этого зверя в мировоззрении и ритуальной практике хакасов. Хронологические рамки работы охватывают конец XIX - середину XX в. Выбор таких временных границ вызван состоянием источниковой базы по теме исследования. Основными источниками являются опубликованные этнографические и лексические сведения, а также фольклорные материалы по обозначенной теме. Методология. Ведущим в работе является принцип историзма, когда любое явление культуры рассматривается в развитии и с учетом конкретной ситуации. Применяются историко-этнографические методы: пережитков (реликта) и семантического анализа. Результаты. В работе впервые систематизированы и проанализированы историко-этнографические и фольклорно-лингвистические материалы по рассматриваемой теме. Введены в широкий научный оборот фольклорные сведения отрывки из хакасских героических сказаний - алыптых нымах'ов, впервые переведенные автором на русский язык. Охарактеризованы место и роль лисицы и ее образа в утилитарной и обрядово-символической практике народа. Выводы. Исследовав проблему, автор пришел к выводу о том, что лисица выполняла важную роль в культуре хакасов. В их быту и практической деятельности этот зверь был ценен и востребован своим мехом, обладавшим высокой материальной и символической ценностью. Лисьи шкуры широко использовались для внутреннего потребления при изготовлении одежды и в качестве платежного средства. В традиционном мировоззрении хакасов образ лисицы наделялся высоким семиотическим статусом. Во многом он был детерминирован биологическими особенностями этого животного, в частности, его внешними зоологическими характеристиками, высоким интеллектом, поведением и, конечно же, средой обитания. Мифологический образ лисицы тесно связан 
с представлением о небе и небесных объектах и наряду с этим имеет прямое отношение к нижним сферам мироздания и ее демоническим обитателям. В религиозно-мифологических воззрениях лисица наделялась чертами медиатора. Вместе с тем в религиозно-мифологических воззрениях народа обнаруживается прямое отождествление лисицы с женским началом, в котором совмещаются как положительные, так и отрицательные черты.

Ключевые слова: хакасы, культура, верования, образ и символ, шаманизм, фольклор, эпос, тӥлгё 'лисица'

Для цитирования: Бурнаков В. А. Образ лисицы в культуре хакасов (конец XIX - середина XX в.) // Oriental Studies. 2020. T. 13. № 1. C. 75-92. DOI: 10.22162/2619-0990-2020-47-1-75-92

UDC $397+398$

\title{
Image of Fox in Khakas Culture: Late $19^{\text {th }}-$ Mid-20 $^{\text {th }}$ Centuries
}

\author{
Venariy A. Burnakov ${ }^{1}$
}

${ }^{1}$ Institute of Archaeology and Ethnography, Siberian Branch of the RAS (17, Lavrentiev Ave., Novosibirsk 630090, Russian Federation)

Cand. Sc. (History), Senior Research Associate

(iD) 0000-0001-9636-3081. E-mail: venariy@ngs.ru

(c) KalmSC RAS, 2020

(c) Burnakov V. A., 2020

Abstract. Introduction. The article analyzes a key zoological image of fox in everyday life, socioregulative, and ritual practices of the Khakas people. Goals. The work aims at delineating the image of fox in respective ethnic cultural contexts, and seeks to identify its role in everyday life and household activities, estimate significance of the animal manifested in Khakas worldview and ritual practices. Materials and Methods. Analyzed are late $19^{\text {th }}-$ mid-2 $0^{\text {th }}$ century published ethnographic, lexical, and folklore materials. The key research principle employed is that of historicism which helps view each cultural phenomenon as an extensive process determined by respective actual conditions. History and ethnography research methods include those of relict examination and semantic analysis. Results. The paper is the first attempt to systemize and analyze historical, ethnographic, folklore, and linguistic materials dealing with the topic. It introduces some folklore texts, such as Russian translations of fragmented Khakas heroic tales - alyptyg nymakh, characterizes the role of fox image in mundane and ceremonial practices of the ethnos. Conclusions. The study concludes the fox used to be essential enough to Khakas culture, which was due to its valuable fur and related symbolic (social status) advantages. Fox skins were used for traditional clothing and as a means of exchange. The Khakas people endowed the fox with high semiotic ranks, largely determined by its biological properties, such as zoological characteristics, acute mind, behavior, and living environment. The mythological image of fox is closely related to the Heaven and celestial objects, being simultaneously associated with lower (underground) realms and their demonic inhabitants. So, according to religious and mythological beliefs, the fox would often act as mediator. However, the cultural tradition tends to identify fox with woman and female principle at large, the latter including both positive and negative features attributed.

Keywords: Khakas, culture, beliefs, image and symbol, shamanism, folklore, epic, тӥлгё 'fox' For citation: Burnakov V. A. Image of Fox in Khakas Culture: Late $19^{\text {th }}-$ Mid-20 ${ }^{\text {th }}$ Centuries. Oriental Studies. 2020. Vol. 13. No. 1. Pp. 75-92. (In Russ.). DOI: 10.22162/2619-0990-2020-47-175-92 


\section{Введение}

Животные с древнейших времен являются неотъемлемой и важной частью природного окружения, хозяйственной деятельности и мировоззрения человека. Образы животных являются одними из ключевых в духовной культуре многих народов мира, в том числе и хакасов. В быту, мифологии, фольклоре, традиционных верованиях и обрядности хакасов часто встречается образ лисицы (хак. тӥлгӱ). К сожалению, вопросам выявления и изучения мировоззренческого комплекса об указанном животном до сих пор не уделено должного внимания в хакасской этнографии и фольклористике. Целью работы является характеристика образа лисицы в культуре указанного народа.

Лисица в быту и практической деятельности

Обширный ареал обитания и повсеместная распространенность этого животного, а также его красивый и ценный мех всегда привлекали к нему внимание людей [Щукин 1847: 417].

Лисица являлась и остается одним из важных объектов охотничьего промысла. Интерес к ней, как уже отмечено, связан с ее весьма привлекательным и дорогостоящим мехом, который и по сию пору широко используется при изготовлении одежды и пр. Наибольшее распространение среди хакасов получил головной убор, либо полностью сшитый из шкуры этого животного, либо с ее частичным применением. При этом в быту такие шапки носили и продолжают носить как мужчины, так и женщины.

Известный ученый XVIII в., академик Г. Ф. Миллер, описывая обозначенный элемент одежды указанного народа, сообщал: «Женские шапки у татар [хакасов. - B. Б.] и брацких по большей части оторочены мехом серой лисицы (душки), мужские шапки мехом с лисьей спины. Оторочку мужских шапок в зимнее время при больших холодах можно опускать, чтобы предохранить лицо» [Миллер 2009: 127].

Среди женских головных уборов наиболее дорогими и престижными считались те, которые были сшиты из меха черно-бурой лисицы. В традиционном хакасском обще- стве обладание подобным предметом гардероба указывало на высокий социальный статус и материальный достаток его хозяина (чаще - хозяйки) и ярко выделяло его среди всех остальных сородичей [Кропоткин 1895: 32; Костров 1884: 211; Шибаева 1959: 68-69].

Наибольшую распространенность и известность у хакасов, особенно среди этнической группы качинцев получила тӥлгё пӧрік 'лисья шапка'. Ее шили из меха черно-бурой или красной лисицы. Указанный головной убор являлся обрядовым и обычно надевался лишь по праздникам, в том числе и на свадебную церемонию. Ю. А. Шибаева совершенно точно заметила, что ее обладательницы гордились им и особо берегли. Их в каждом улусе бывало лишь одна-две, потому что стоили они дорого [Шибаева 1959: 70]. Оригинальные сведения о тӥлгӱ пӧрік встречаются в работе А. А. Кузнецовой и П. Е. Кулакова «Минусинские и ачинские инородцы» [Кузнецова, Кулаков 1898: 169-170]. Приведем их: «Женские шапки, предназначенные для праздников и свадеб, шьются совершенно иначе и надеваются и зимой, и летом. Тюлгю пюрик (лисья шапка) надевается одними лишь замужними женщинами, принимающими участие в свадьбе, главным же образом свахою, а также иногда и самою невестою (ул. Морозов на Сырах, Аск. У.). Тюлгю пюрик же надевает и молодуха, когда едет в определенный для мировой срок обыкновенно чрез год после свадьбы, к своим родителям (Синяв. ул., Аск. У.). Эта шапка шьется всегда из лисьего меха, у богатых из дорогой черно-бурой лисицы. Высокий меховой околыш подбивается какой-нибудь дорогой материей и идет вокруг головы в виде большого кокошника с разрезом позади. В окружности околыш имеет от $1 \frac{1 / 2}{2}$ до 2 арш. длины. Круглая тулья из парчи или шелковой материи почти совершенно скрывается за высоким околом; она собрана посредине и к ней сверху пришита большая шелковая кисть. Надевается тюлгю пюрик поверх платка прямо на лоб. Стоят от 70 до 500 руб. В настоящее время эта свадебная шапка сохранилась в Абаканской и Аскизской Управах; у кизыльцев тюлгю пюрик теперь уже не встречается, но ста- 
рики помнят, что лет 30-40 т. н. эту шапку еще надевали на свадьбах (ул. Оракский и Костинский)».

У хакасов в прошлом бытовал обычай, имеющий отношение к традиционным охотничьим нормам. Суть его сводилась к следующему. Добытую лисицу охотник отдавал девушке - победительнице в килін чарыс» 'состязание невест', которое организовывалось в связи с указанным событием. Согласно правилу, одержавшая победу должна была из лисьего меха изготовить для себя шапку свахи тӥлгё пӧрік [Бутанаев, Монгуш 2005: 93].

Обратим внимание на то, что в традиционной культуре каждого народа и хакасов, в частности, сваха выполняла важную связующую роль в процессе взаимодействия двух родов - жениха и невесты. Во многом от ее харизмы, житейской мудрости, искусной речи и прочих факторов зависел успех заключения брачного союза. В данных обстоятельствах немаловажное значение придавалось традиционному костюму свахи, обладавшему широким семиотическим по- лем и создававшему ей особый ореол. Одним из неотъемлемых и маркирующих его элементов наряду с идектіг тон 'шубой' и пово 'нагрудником' была шапка - тӥлгё пӧрік. Поэтому не лишена оснований мысль некоторых исследователей о том, что «в любой традиционной культуре сваха - это особый человек, задачей которого является любым способом добиться самого выгодного варианта заключения сделки для стороны жениха. Образ свахи в какой-то степени соответствует образу хитрой, изворотливой лисицы. В этой связи шапка из лисы расценивалась, на наш взгляд, как предмет, призванный помочь свахе» [Содномпилова, Нанзатов 2016: 55].

Образ тӥлгй пӧрік, столь важного элемента женского гардероба, нашел отражение и в фольклоре, например в загадке: Узун авас пазында улуг хус одырча (тӥлгӱ пӧрік) 'На вершине высокого дерева сидит большая птица (лисья шапка свахи)' [Доможаков 1951: 77]. Отметим и то, что тӱлгӱ пӧрік часто фигурирует и в героических сказаниях — алыптыz ныммах' ax:
Алтын Арыг абахайы,

Хара тӥлгё пӧрігін хамавына сальп,

Хара торвы кибін иңніне кизіп,

Адазының ибін кӧре,

Пала хас чіли пайбаңунап,

Пузур хас чіли пуйбаңнап,

Пас килеедір

\author{
Алтын Aрых чачалары \\ Ала маңных тонын арвазына кискен, \\ Хара тӥлгӥзін хавыйта салван
}

'Алтын Арыг красавица,

[Из] черной лисицы шапку [на] лоб натянув,

Черное шелковое одеяние на плечи надев,

[На] отчий дом глядя,

Подобно гусенку переваливаясь, идет

Словно большой гусь, покачиваясь,

Подходит'

[Кӧк Хан 1974: 39]; (перевод наш. — В. Б.).

'Алтын Арығ старшая сестра [их]

Пёструю просторную шубу [на] спину надела,

[Шапку из] черной лисицы, [на] голову [с размаху] надела'

[Алтын Тайчы 1973: 113]; (перевод наш. — В. Б.).
Столь значимая роль, отводимая шапке из лисьего меха в церемониальной практике хакасов, способствовала перенесению ее образа и в шаманскую обрядовую поэзию. В традиционных воззрениях народа одними из самых почитаемых божеств Среднего мира являются таз ээлері 'горные духи'. Они осмысляются не только в качестве наиболее влиятельных земных духов-хозяев, но еще и далеких предков. В религиозно-ми- фологическом сознании хакасов тах ээлерi часто представали в антропоморфном виде. Полагали, что на головах они носят лисьи шапки. В молитвенных обращениях к ним всегда акцентируется внимание на указанном предмете их гардероба: «[О горный дух — покровитель бурых коней] ноги твои ступают на белые хребты, полы касаются извилистых гор! Шапка у тебя из черной лисицы, кнут — из черной выдры!»; «(О владыка, 
горный дух) обмахиваешься ты белыми и синими лентами, ездишь верхом на сине-сивом коне, сбруя (твоего коня) - серебряная узда, шапка (у тебя на голове) — из красной лисицы!»; «[О горный дух] ездишь ты верхом на черно-буром коне, кнутом тебе служит черная выдра, шапка твоя - черная лисица, жертвуется тебе богатая водкою кадка!» [Катанов 1907: 554-555, 557].

В прошлом зажиточные хакасы использовали лисий мех не только для изготовления шапок, но и шили из него шубы - идектіг тоннар [Шибаева 1959: 78, 84]. Подобное практическое применение шкуры рассматриваемого зверя нашло отражение и в эпическом творчестве. В нем нередко встречаются сюжеты, согласно которым богатыри, устраиваясь на ночлег, укрываются шубой / одеялом из меха черной лисицы [Катанов: 1887: 221-222; Катанов 1907: 183-184].

Таким образом, в традиционной культуре хакасов, как и других народов, шкура лисицы и иных зверей имела не только высокую материальную, но и символическую ценность, связанную с престижным потреблением. Она всегда была востребована. Все это естественным образом приводило к тому, что пушнина издревле выполняла еще и денежную функцию и служила в качестве распространенного предмета торгового обмена [Потапов 1952: 53]. Помимо того, как известно, в прошлом этот товар являлся одним из основных видов дани - албан. Не- пременной ее составляющей был мех лисицы и иных пушных зверей. Так, например, в 1644 г. красноярский воевода об этом явлении у предков хакасов - енисейских кыргызов, сообщал: «В Тубу приезжают калмыки и мугалы и емлют с кыргыских людей и с тубинцев ясак некладной, 310 скотин емлют 10-ю скотину, сверх мягкой рухляди, соболей и лисиц, и бобров, и кошолоков» (цит. по: [Потапов 1952: 57]). В XVIII в. после присоединения Хакасии к Российской империи и вплоть до XIX в. взимание в государственную казну ясака в виде пушнины продолжилось [Потапов 1952: 110; Кузнецова, Кулаков 1898: 92; Чудновский 1885 : 5; Щукин 1847: 409, 411].

Сибирская пушная продукция всегда пользовалась огромным спросом на внутренних и международных рынках. Указанная реалия в итоге привела к бесконтрольному и хищническому использованию соответствующих биоресурсов. В результате чего уже к XIX в. произошло значительное сокращение пушного зверя в Сибири и Хакасии в том числе. Падение добычи соответствующих диких животных привело к некоторому дефициту на рынке, а значит и росту цен на пушнину. В этой связи вызывает интерес динамика цен на этот товар в Хакасии, происходившая более 50 лет торговля пушниной, а также конкретный вид пушнины, который добывался:

Таблица 1. Динамика цен на пушнину в Хакасии в 1840-1896 гг.

[Table 1. Dynamics of Prices for Furs in Khakassia, 1840-1896]

\begin{tabular}{|l|c|c|c|c|c|c|c|}
\hline $\begin{array}{c}\text { Цены в рублях } \\
\text { за годы }\end{array}$ & 1840 & 1850 & 1860 & 1870 & 1880 & 1890 & 1896 \\
\hline Медведь & 4.1 & 3.0 & 6.4 & 7.1 & 5.8 & 7.0 & 12.5 \\
\hline Волк & 2.1 & 1.6 & 2.8 & 2.3 & 2.9 & 2.8 & 2.8 \\
\hline Соболь & 3.2 & 3.0 & 5.5 & 7.5 & 8.3 & 9.0 & 7.3 \\
\hline Белка & 0.07 & 0.10 & 0.12 & 0.13 & 0.16 & 0.9 & 0.11 \\
\hline Лисица & 2.1 & 3.0 & 4.1 & 5.5 & 4.5 & 5.5 & 5.7 \\
\hline
\end{tabular}

[Кузнецова, Кулаков 1898: 91].

Итак, широкая распространенность лисицы, престижность потребления ее меха и обусловленная этим постоянная востребованность на рынке способствовали росту интереса к ней в обществе. Данные реалии до поры до времени стимулировали развитие пушного промысла. Применялись новые методы добычи этого зверя. Все это, безусловно, требовало хороших знаний о нем - главным образом, особенностей его биологического поведения и повадок. Вместе с тем в традиционной культуре хакасов знания о лисице носили не только рациональный, но и иррациональный характер. Религиозно-мифологические воззрения хакасов о лисице, как и о других животных, формировались задолго до развития и активизации пушного промысла. Представления о ней, несомненно, своими корнями восходят к архаическим пластам верований. 


\section{Религиозно-мифологические воззре- ния о лисице}

В культуре хакасов, как и многих других народов, лисица неизменно выступает универсальным и ярким символом хитрости, ловкости и плутовства. Эти ее качества широко представлены в устном народном творчестве и обыденной речи. Образ лисицы с обозначенными чертами характера, порой даже и возведенных до комического уровня, отображают лишь одну из граней ее сложного и неоднозначного образа. Отметим, что изучение этого вопроса в дальнейшем будет предметом подробного рассмотрения нами в отдельно взятой статье.

В космогонических представлениях хакасов образ лисицы нередко ассоциируется с отдельными небесными светилами. Так, Н. И. Попов зафиксировал у хакасов уникальный миф «Семизвездница или Большая Медведица» с известным мотивом небесной охоты. Приведем его: «Старик охотник гонялся за семью лисицами на земле и загнал их так далеко, что попал с ними и на небо. Там лисицы сделались семью звездами, и охотник тоже стал звездою, которая находится на востоке от Семизвездицы» [Попов 1884: 646]. Среди хакасов и других сибир-

\author{
Хара тавның тӥлгӥзін, \\ Хара адым читсе, соххайбын; \\ Харваларның хыстарын, \\ Халиим читсе, аларбын. \\ Сарыг тавның тӥлгёзін, \\ Сараадымм читсе, соххайбын; \\ Сарыгларның хыстарын, \\ Савызым читсе, аларбын.
}

Азыр тагның тӥлгйзін

Аттых сӥрзеңер, тударзар;

Алар ползанар позымны,

Адам чіріне парарзар.

Игір тайганың тӥлгӥзін,

Ибір пілзеңер, тударзар;

Изертер ползаңар позымны,

Инем чиріне парарзар. ских народов встречается и другой вариант этого мифа. При этом его главными персонажами являются охотники с собаками и маралы [Мифы 2006: 11].

Связь образа лисицы с небом, включая некоторые объекты и явления, имеющие отношение к нему, обнаруживается и в культуре монгольских народов. Так, например, буряты полагали, что лиса, наряду с волком, имеет небесное происхождение. Более того, в их мифологических представлениях солнце и радуга порой соотносятся с образом указанного зверя [Николаева 2010: 277-283; Содномпилова, Нанзатов 2016: 49-50].

Лисица - воплощение женского начала

В традиционной культуре хакасов образ лисицы устойчиво отождествляется с женским началом. В мифологическом сознании народа заключение брачного союза символически соотносится с процессом добычи обозначенного зверя. Подобные представления нашли отражение в фольклоре. В нем добытая охотником лисица нередко олицетворяет собой желанную невесту [Унгвицкая, Майногашева 1972: 245]. Соответствующие ассоциации широко представлены в народных песнях - maxnax'ax:

'Коль черной горы лисицу

Карий конь мой догонит, убью;

Жену из рода Харга,

Коль калыма хватит, — возьму.

Коль желтой горы лисицу,

Конь мой соловый догонит, убью;

Жену из рода Сарыг,

Коль смекалки хватит, — возьму'

[Хакасские ...1980: 32].

'С двуглавой горы лисицу,

Если на конях погоните, поймаете;

Если сватать хотите меня,

В отцовскую землю приедете.

С крутой горы лисицу,

Сумеете окружить - поймаете;

С собой, если хотите меня увезти,

В материнскую землю приедете'

[Хакасские... 1980: 56]. 
«Под красный камень красная лисица заскакивает, когда человек заревет; к лисе красная девка придет - когда я закричу. Под черный камень черная лисица бежит, когда ее испугаешь; ко мне придёт девка с черной косой - когда я плетью постращаю» [Островских 1895: 329].

Вместе с тем в приведенном фольклорном материале, наряду с устойчивой мифологической ассоциацией «лисица - девушка», выявляется такое реальное социокультурное явление, как дарообмен. В свадебной традиции хакасов и других народов он бытовал в виде выплаты калыма за невесту. В прошлом плата за невесту, помимо домашнего скота и прочих материальных ценностей, могла включать в себя еще и лисьи шкуры. Подтверждение тому также находим в известной народной поговорке:

Хызыл тӥлгӥ ахчаа турчан,

'Красная лисица денег стоит,
Хыс кізі хальцца турчан

Девушка стоит калыма'

[Мудрое слово 1976: 96].

Обратим внимание на то, что в традиционном сознании указанная пушнина, помимо сугубо утилитарного, имела еще и высокое символическое значение. Лисица, непосредственно олицетворявшая собой женское начало, в семиотическом плане была равноценна девушке-невесте. Таким образом, в процессе брачного договора между двумя родами производился своеобразный равнозначный символический обмен «баш на баш».

Образ суженой невесты, предстающей перед богатырем в образе красной лисицы и своей мистической силой призывающей его к себе, встречается в одном из хакасских героических сказаний. Приведем соответствующий отрывок из указанного произведения:
Андаг кӱннернің пірсінде,

Таңның харазы тӥскенде,

Хызыл от чіли савылыл,

Хызылл мерчікті сёрізіп,

Хан Тӧністің алнынцฺа

Хызыл тӥлгё ӱкёс салван.

Таң хараазында хызыл тӥлгё

Таңнастыз сіліг чалбыраан.

Тырвах узынаң хаап ала,

Хызыл мерчікнең ол ойнаан.

Турган орнында mыlbin nарылn,

Танунабаали танунидыр,

Чапсыбаали чапсидыр

Альпп чахсызы Хан Тӧңіс.

Олганда кӧрген таңназы

Онмас сілиинең салвылча,

Альип ӥлӥзін алвапча.

Хызыл тӥлгӱ, сегір киліп,

Хызыл мерчікті, кил, тастаан

Хан Тӧнуістің хойнына кире.

Тӱстен усхуна чачьраан чіли,

Тітіри тӥскен ирнің чахсызы.

Харбанып ала кӧр турза,

Хызыл мерчігі хойнында.

Xaman xapan кӧрібіссе,

Хызыл тӥлгӥнің ізі дее човыл.

Хайзы-хайзы чирлерде

Харых ачыстыльв кӧг чайылчча,

Хайхастыз сарын истілче:

- Хырыза micmiг хара чир теербен

Хырых айланыл тартылыл тур ноо,
'В один из таких дней,

[Когда] предрассветная тьма отступила,

Красному огню подобно искрясь,

[Когда он за] красным мячом гонялся,

Перед Хан Тонисом

Красная лисица промчалась.

[B] предрассветной темноте красная лисица

Изумительно красиво просияла.

Когтями [своими] хватая,

[C] красным мячом она играла.

На том месте, где стоял, [так и] застыл [он],

Удивляясь, изумляется,

Поражаясь, восторгается

Лучший из богатырей Хан Тонис.

[В] детстве виденное, диво

[Этой] красотой [был] взволнован,

Богатырь [свою] судьбу благодарит.

Красная лисица, прыгнув вдруг,

Красный мячик неожиданно бросила

Хан Тонису прямо [в] его объятия.

[Словно] ото сна [резко] очнувшийся [человек],

Вздрогнул муж достойнейший.

Ощупывая [то место] видит,

Красный мячик на груди [у него].

Снова взглядом окинул [вокруг],

Красной лисицы [и] следа нет.

[B] каких-каких землях

Тоскливая мелодия разливается,

Удивительная песня слышится:

- Сорок зубов [у] черной земли [она подобна] мельнице,

- Сорок [раз] провернувшись, мелет она ведь, 
Хызыл чӥреемні аптап салван Ах хардан арыв авох чӥзінніг Абахай тӧреем альп Хан Тӧңъіс,

Ал позымны албас таа ползаң, Адам чиріне айбынмин килдек, Авылахтап сӧлир сӧзім пар полчуац. Отыза тістіг ойлаңа теербен Отыс айланып тартылыл тур ноо, Олганнаң ӧӧзім ӧстедіп чӧрген Час хардан нымзах чавбан чӥректіг Чалахай тӧреен сіліг Хан Тӧнісі,

Изертпезең, дее ирке позымны, Ічем чиріне ибіріліп килдек, Изептеп сӧлир сӧзім пар полчац. Читі азыр пастыг чікім Кӧӧк тасхыл

Адамның чирі савынча полар. Читі талайның пилтірі полван Ічемнің чирі чиксепче полар
“Красное сердце [моё] очаровавший, Белого снега чище [c] белым лицом Красавцем рожденный богатырь

Хан Тонис,

[Если] даже меня не возьмёшь [в жёны],

[B] землю отца [моего] не задерживаясь, приезжай, Мудрые слова [для] беседы [с тобой] имеются.

О тридцати зубьях быстро [вращалась] мельница, Тридцать раз промолов, остановится [ведь], [C] детства [из] горла стоны [издавая], ходивший, Свежего снега мягче [c] добрым сердцем Приветливым рожденный, красивый

Хан Тонис,

[Даже если] не увезёшь с собой ласковую меня,

[В] землю матери [моей] обойдя, приезжай,

Благоразумные слова [для] беседы [с тобой] имеются.

О семи раздвоенных вершинах отвесная [гора] Кӧӧк тасхыл

[O] земле отца [моего] думает, наверное.

Семи морей устье [которых] было

Землёй матери [моей] тоскует, наверное'

[Хан-Тонис 2007:299-301]; (перевод наш. — В. Б.].
О связи образа лисы с феминностью свидетельствует наличие в культуре хакасов соответствующих имен. В фольклоре хакасов чрезвычайно распространенными были женские «лисьи» имена. Среди героинь часто встречаются такие имена, как: Алтыл Тӥлгё ‘Золотая Лисица’, Тӱлгӱ Хызыл 'Красная / Рыжая Лисица', Тӥлгё Арых 'Чистая Лисица', Тӥлгё Хыззыл Алып 'Красная Лисица богатырша', Тӥлгё Хысс 'Лисица-Дева’ и пр. [Катанов 1887: 234; Тӱлгё-хызыл 1951: 35, 154; Хан Орба 1989: 204; Субракова 2007: 62, 159, 160].

Отметим то, что образ лисицы как воплощение женского начала встречается не только у хакасов, он обнаруживается в культуре других сибирских народов. По сообщению Н. Н. Николаевой, у бурят «лисе (унэгэн) лексически часто сопутствует определяющее слово эзы (варианты: эзии, изы) 'женщина', 'баба', в отношении животных 'самка'» [Николаева 2010: 280]. Вызывает глубокий интерес то, что якуты в процессе

Анаң андар Пора Нинчзі,

Тыр сілігін сальпсхан.

$\ddot{У}_{с}$ хулас сунныз хара тӥлгӱ польи,

Киріліп-сееліп, ойлап сыххан охотничьей обрядности на добытую лисицу обычно надевали женское серебряное украшение [Алексеев 1975: 44]. Тем самым, очевидно, манифестируя ее женскую ипостась.

В эпическом творчестве хакасов одним из самых распространенных является образ женщины-богатырки, которая наравне с мужчинами защищает родную землю и свой народ от всевозможных врагов. Как справедливо замечает Н. В. Шулбаева, в ее образе «органически синтезированы черты мифологизма, женственности и богатырства. Например, образ Пора Нинчи в алыптығ нымах'е «Тошпах харахтығ Пора Нинчі («Пучеглазая Пора Нинчи»), записанного от великого хакасского сказителя П. В. Курбижекова, представлен не только как хранительницы очага, заботливой матери, но и как богатырки» [Шулбаева 2016: 90]. Примечательно то, что указанная героиня в процессе борьбы с подземными существами оборачивается именно в лисицу черной масти - хара тӥлгй:

'Затем Пора Нинчи

С шумом встряхнулась.

Трехсаженной черной лисой став,

Вытянувшись, помчалась'

[Шулбаева 2016: 90]. 
В эпосе «Алтын Арығ» [Алтын Арыг Плё-Харын» для свершения своих подвигов 1988: 48, 290] героиня по имени «Пис-тумзух- также принимает вид черной лисицы:

Алты айланыл, абахай чахсы,

Читі ибіріліп парыл,

Тырлада сілігінгенде,

Хара тӥлгӥ польбысхан
'Шесть раз благородная женщина туда-сюда прошлась,

Семь раз повернулась,

С шумом встряхнулась -

Черной лисицей обернулась'
В героическом сказании «Ай Мічікнің и Кӱн Мічік» [Ай Мічікнің 1993: 23-24] бо- гатырка Алтын Сас, скрываясь от преследователей, опять-таки превращается в лисицу:
Альпп кӱчӥннер мында суулас турлар

- Альп тӧреен Алтын Састь

Чир ӱстӥн читі кіресті сӥр чӧрдібіс,

Чир дее чит полбадыбыс.

Хызыл тӥлгӥ кибіне

Кіріп тискен тісчелер

Хара тӥлгё польгп

Чир алтына кір чӧрібіскен тісчелер.

Альлп кӱчӥннер аның соонаң,

Чаза mydыл, чаза хаan,

Кір чӧрібіскеннер чир алтьна

\section{Неординарные свойства лисицы}

В эпических повествованиях хакасов лисица наделяется такими эпитетами, как: аң кӥлӥгі '[самая] проворная / храбрейшая из зверей' [Алтын Арыг 1988: 48-49, 290; Хакасский героический 1997: 220-221], кӱлӱк тӧреен 'удалою рожденная' [Кильчичаков 1946: 76] ${ }^{1}$ и пр. Надо полагать, что обозначенные мифопоэтические определения, часто применяемые по отношению к образу лисицы, не случайны. Во многом они детерминированы ее биологией. Как известно из зоологии, у этого зверя отличный слух и нюх, а также сильно развита наблюдательность и зрительная память, благодаря чему он хорошо ориентируется в пространстве и легко адаптируется к различным внешним условиям. Помимо того, лисица очень ловка, вынослива, изобретательна как в охоте, так и при уходе от преследования врагами [Герасимов 1950: 14-18].

В. И. Вербицкий, фиксируя мнения алтайских охотников о незаурядных способностях лисицы, отмечал: «Лисица и ночь переночует, а [нужный ей] след найдет» [Вербицкий 1993: 233].

\footnotetext{
${ }^{1}$ Перевод наш. - B. Б
}

'Богатыри-силачи здесь зашумели:

— Богатыркой рожденную, Алтын Сас

[По всей] поверхности земли семикратно

крест-накрест преследовали,

Земли так и не достигли.

[B] шкуру красной лисы

Облачившись, [она] убежала, говорят,

Черной лисой став,

Под землю ушла, говорят.

Богатыри-силачи после этого,

Не поймав, не схватив [ее],

Последовали [за ней] под землю'

[Ай Мічікнің 1993: 23-24]; (перевод наш. — В. Б.).

Вызывает глубокий интерес суждение известного охотоведа С. О. Лосева, основанное на длительном наблюдении за поведением лисицы в разных ситуациях: «Ум, хитрость, находчивость, изворотливость, сметливость и необыкновенное умение в минуту неизбежной гибели пользоваться самыми ничтожными средствами и случаями и с помощью их в глазах своего грозного преследователя извернуться, обмануть, проскользнуть, как ртуть между пальцами, и исчезнуть, как дым от ветра, - вот качества этого проворного и увертливого зверька» [Лосев 2007: 76].

Любопытство, чрезвычайная подвижность и юркость лисицы в традиционном мышлении формировали представление о ней как о существе, находящемся в состоянии постоянного поиска и движения, а зачастую и неуловимом. В хакасских сказках, по-видимому, не случайно приводится сюжет, согласно которому богатырь получает предостережение от бесперспективной попытки добыть лисицу ввиду ее неуязвимости: «Давешний рыжий конь его теперь заговорил: „О Кан Иргек (царь - большой палец), не только ты, но даже твои родственники и потомки не поймают 
чёрной лисицы!” [Катанов 1907: 296]. В мифологических воззрениях хакасов бытовала убежденность в том, что этот зверь способен преодолеть любые запредельные пространства. Подобные представления нашли отражение и в эпике:
Саасхан тӥспес сарыз чазылар, Хусхун тӥспес хуу чазылар

Ир соонда кӧп халчалар. Aт чорыгында парчатса, Хызыл тӥлгӥ удур чӥгӱрчедір

Чирнің ӱстуӥн читі толви

Чӱгуртіп-париван туста

Кӥлйк тӧреен хара тӥлгёниң,

Кискен кичиглері поразынаң халадырлар

Асхан пирік тавлары

Тозынныв халадырлар.

Хадарван малның ізі-чольнна

Хара тӥлгӥ тӥскен,

Хумныз чахсы чазыда

Хальх сальпп ойлабысхан.

Тилегейде чирде тігірті чох килеедір,

Хан тигірнің паарында

Савбазы чох полган,

Узун ӧс парван оттьл

Уйби паспин килеедір.

Чалбах пӱрліг оттарнь

Чабыра паспин килеедір,

Ханаттыз часхсы хус чіли,

Алтыл кӱнніг чирні

Ан кӥлӱгі тобырван
Халлап, сииліп одыр,

'Желтых степей, [где] сорока не садится, Белесых степей, [где] ворон не опускается, Позади мужчины много [земель] остается. [В то время как] лошадь [его] рысью идёт, Красная лисица навстречу бежит'

[Ай Мічікнің 1993: 49]; (перевод наш. - В. Б.);

'Поверхность земли семь [раз] кругом [объезжая], [И во] время этого бега

Удалою рожденной черной лисицы

Пробегаемые [ею] малые [горы] с пылью оставались Преодолеваемые [ею] труднопроходимые горы В пыли оставались'

[Кильчичаков 1946: 76]; (перевод наш. — В. Б.);

'По следу-пути пастбищного скота

Черная лисица пустилась,

По песчаной степи

Быстро она побежала.

По земле бесшумно она бежит,

И в глубине неба-хана

Примет ее нет.

Высокой травы

Не приминая, бежит,

Широколиственные травы

Не придавливая, бежит,

Как крылатая хорошая птица,

Взлетает она и парит.

Расстояние, [равное] шести дням [пути],

Проворный зверь пробежал'

[Алтын Арыг 1988: 48, 290].

К сказанному следует добавить и то, что в процессе реальной охоты - мышкования лисица нередко появляется вблизи проезжих дорог, по которым регулярно перемещаются люди [Зворыкин 1929: 14; Сугробова 2004: 9]. В мифологическом сознании хакасов указанные представления, во многом обусловленные конкретными биологическими особенностями ее поведения, способствовали тому, что лисица не только стала напрямую соотноситься с образом «пути-дороги», но ее еще и наделяют признаками медиатора, осуществляющего связь между мирами. В связи с чем в хакасском фольклоре распространен сюжет, согласно которому герой, увлекшись погоней за лисицей, невольно попадает в потусторонний мир [Овичев 1905:7; Кильчичаков
1946: 73-102].

Лисица в шаманизме и традиционной обрядности

В культуре хакасов ключевым посредником между миром людей и духов, бытием и инобытием традиционно выступал шаман (хак. хам). Его мистическая сила определялась наличием у него духов-помощников - mӧс'ов. Полагали, что чем больше их было, тем более могущественным он являлся. Немаловажное значение при этом имел еще и конкретный состав подчиненных ему невидимых существ, которые, в свою очередь, также разнились своим магическим потенциалом и умением. Среди них были представлены духи, имеющие антропоморные, зооморфные и иные обличия. Одним из известных звериных шаманских духов была 
лисица. Известно, что каждый из подобных сверхъестественных существ символически обозначался на шаманских атрибутах — костюме и бубне. Сильные шаманы — nувдуры нередко изготавливали cblзыlм - сакральные ленты из шкур лисицы и выдры [Бутанаев 2006: 79].

Согласно этнографическим сведениям, в арсенале шаманки Тади Бурнаковой присутствовал дух-помощник под названием Товыс Хара Тӥлгё иліг хурльг оолвы 'Девять Черных Лисиц с пятьюдесятью поясами парень' [Сагайский обряд 1998]. Следует заметить, что выбор указанного зверя в качестве мистического помощника $x a м$ ' $а$, очевидно, был не случаен. В религиозно-мифологическом сознании хакасов лисица благодаря своему уникальному тонкому чутью воспринималась в качестве существа, способного видеть невидимое, слышать неслышимое и предугадывать предстоящее.

В традиционной обрядовой практике хакасов вместе с тем важное место отводилось сакральным изделиям, имевшим подобную же номинацию, - тӧс. В конце XIX в. соответствующие фетиши встреча- лись практически в каждой семье. Обратим внимание на факт того, что культовые предметы - möc'bl не имели никакого отношения к тӧc'aм - духам-помощникам шамана. Более того, они выполняли совершенно иную роль. Тӧс'bl-фетиши служили в качестве постоянных семейно-родовых духов-охранителей и покровителей обычных людей. В то время как mӧc'bl шамана помогали непосредственно только ему и лишь в процессе камланий и иных сакральных действ. А в остальное время они жили своей жизнью на различных территориях.

Töc'bl-фетиши постоянно располагались как внутри жилища, так и в иных местах. Выполняли защитную, лечебную, покровительственную и иные функции. Одним из распространенных среди них был тӥлгё тӧс 'лисий фетиш'. Хакасы были убеждены, что он помогал в ситуации трудных родов, а также при заболеваниях груди, спины, головы, ног и пр. [Бутанаев 2003: 134; Бурнаков 2016: 32-35]. В процессе отправления ритуала к нему часто обращались со следующими словами:

\author{
Хызыл тӥлгее хубасхазын! \\ Хырдаң хырва син чортхазың \\ Ой тӥлгее хубасхазын! \\ Ой пазынаң син чортхазың
}

'Ты превратился в рыжую лисицу!

Ты бегаешь по холмам,

Ты превратился в желтую лисицу!

Ты бегаешь по вершинам логов'

[Бутанаев 2003: 224].
В народе верили, что, помимо своих основных функций, дух лисицы способен был еще и нейтрализовать негативные последствия дурного сна [Бутанаев, Монгуш 2005: 102].

\section{Связь лисицы с Нижним миром}

В традиционном мировоззрении хакасов животные, обитающие в воде, норах, скальных расщелинах и иных подобных местах, воспринимались в качестве существ, тесно связанных с Нижним миром. К их

Ӱр бе, ас па полванда,

Ах пайзаңның істінең

Хызыл тӥлгё cызылn,

Чӥгёр парыл, хызыл талайга кірді.

Аның, соонца ах пайзаңның істінен,

Ала тӥлгё cызыın, чӥгёр nарып,

Хызылл тӥлгё хайдаң кірген,

Аннаңох кіре халды.

Ӱзінціізін ах пайзаңның істінең числу причислялась лисица. При этом ее непосредственное отношение к обозначенной сфере мироздания обусловливалось не только биологической реалией того, что она живет и воспроизводит свое потомство под землей - в норах, но еще и мистической связью с водной стихией. В эпических произведениях хакасов встречается сюжет, когда лисица с различными целями, в том числе ради спасения собственной жизни, погружается в водную пучину:

‘Долго ли, коротко ли было, Из глубин белого дворца Красная лисица, выйдя, Побежав, в Красное море вошла. После нее из глубин белого дворца Пестрая лисица выйдя, [и] побежав, [В то место] где красная лисица нырнула, Туда же бросилась.

[B] третий [раз] из глубин белого дворца 


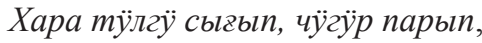

Хызыл талайвох кірді<...>

Хызыл талайдаң хара тӥлгё сывылп,

Ахсы ханына айлыхтыр,

Кӧксі ханына пурлувыл,

Тайваны кӧре ойлабыстыл.
Черная лисица выйдя, побежав,

[B] Красное море также нырнула <...>

Из красного моря черная лисица выйдя,

[От] крови [в] пасти [она] захлебывалась,

Грудь от крови вздымаясь,

Прямо в тайгу [она] умчалась'

[Хара Хусхун 1977: 57, 59]; (перевод наш. — В. Б.).
Следует добавить и то, что в хакасском фольклоре дочь водного владыки - Талай $x a$ ' $^{\prime}$ нередко оборачивается в черную лисицу [Потанин 2005: 789].

В религиозно-мифологических представлениях рассматриваемого народа в подземном мире располагалось царство умер-

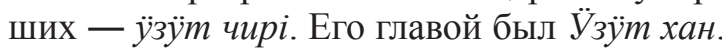
Согласно верованиям хакасов, «у него была дочь - „черная лисица“, которая, принимая вид лисицы, выбегала на землю и делала зло людям» [Орфеев 1887: 181]. В некоторых текстах имеется упоминание о дочери $\ddot{У} з \ddot{m} m х а н а$ в виде пестрой лисицы (ала тӥлгӱ), которая в паре с духом в образе красной лисицы с косами на лбу (хамавында тулуцныз хызыл тӥлгё) причиняет вред обитателям солнечного мира [Хара Хусхун 1977: 63]. Отметим и то, что в устном народном творчестве хакасов помимо того фигурируют еще семь лисиц (читі тӥлгӥ), которые наряду с некоторыми другими животными выступают в качестве охранителей подземного мира и жестоко преследуют непрошенных визитеров [Катанов 1887: 227].

Аналогичные представления бытовали и у бурят. Они воспринимали лисицу в ка- честве «собаки» владыки загробного мира [Николаева 2010: 280]. В алтайских сказках лисицы нередко выступают в качестве дочерей шулмуса - злого духа, живущего в норе [Потанин 2005: 354-355].

В хакасском фольклоре жители Нижнего мира, изначально обладая антропоморфным или иным обличием, для свершения своих злокозненных деяний часто оборачиваются в животных и птиц [Катанов 1887: 230]. Одним из известных хакасских мифологических персонажей подобного рода является ведьма - хуy хат, живущая в глубоком подземелье. Она, как правило, враждебно настроена к людям. Причем в сказочных и иных повествованиях под этим наименованием часто фигурирует даже не одна, а целая группа отрицательных героинь. В процессе подготовки к злодеяниям они часто оборачиваются в черных лисиц. Так, например, в одном из таких произведений сообщается о том, что «младшая ведьма $[x y y$ xam $]$ превращается в черную лисицу и обманывает богатырей, находящихся под землею» [Катанов 1907: 219]. В эпическом творчестве хакасов имеются описания сцены противоборства богатыря и ведьмы хуy хат:
Хара-сувны хастада сах андох Хаалап-сыххан алып оолах Хуу-хаттың тискер чольнаң Хаалап пар-сыххан улуг табрахнаң. Хуу-хат чир алтынаң сыхтыр. Альп тӧреен чалаас оолах пістің Арбын чирии чара-кил сапхан. Чир алтынзар кире сегиртібіскен. Чир алтына тӥзіп, кӧрчетсе Ах чазының арбыи істінде Хырых хулас сынныв ӧскен. Хара тӥлгё сах-ол тимде Адаьин кизире чӥгӱрібіскен - Адамның ачи ползын, Инемнің оохайы ползын! Хырых хулас сынныз тігін. Хыьылап-париган хара тӥлгӥні
'Там, на берегу Черной реки,

[Стал] шагать-ходить [этот] мальчик богатырь

[По] обратной стороне дороги [ведьмы] Хуу-хат

[И] ходить [стал] сильно торопясь.

[Ведьма] Хуу-хат из-под земли вышла.

Богатырем рожденный, голый мальчик наш

Широкую землю [одним] ударом расколол.

В подземелье [прямо] внутрь спрыгнул.

В подземелье спустившись, видит -

В середине широкой белой степи

В сорок саженей высотой выросла.

Черная лисица там наготове

Перед конем перебежала

— [Пусть будет] отцовской горечью,

— [Пусть будет] материнской скорбью!

Сорокасаженную ту [лисицу].

Мчащуюся черную лисицу 
Азыр холларнаң тут-полбазам Ікі хольлм миниң чӧре хурузын! Алтымма мӱнген хара чабавам Аваа читіре ойлан-полбаза

Тӧрт туйвавы суура чачыразын!
[Если] растопыренными руками не поймаю -

[Пусть] обе руки мои отсохнут!

Оседланный мой черный жеребенок

[Если] его не догонит,

[То пусть его] четыре копыта соскочат [и] разлетятся'

[Кильчичаков 1946: 75-76]; (перевод наш. — В. Б.).
В героических сказаниях изучаемого народа, помимо ведьм хуy xam, представлены и другие отрицательные женские персонажи, связанные с подземным миром. Они также

Сайльв сынва сывара ойласхан

Хара кӥмйс тӥктіг ӱс тӥлгй.

Тірледе сілігінібіскеннер,

Хара Нинчі, Пора Нинчі,

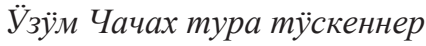

Хара Нинчуінец Очь-Сарых анда

Ах ӧрге ибден сыхтылар:

„, Че, амды Албынчуы ачырган халар“, -

тісчелер,

Хара тӥлгӥ польıп Хара Нинц̧і,

Хуу пӥрр польли Очьл Cарыз

Кӱннің кірізі чирні кӧре

Ойлап парыбыссханнар

Алып Хан Хыс ачьрган турадыр:

- Аданың ачии полды,

Иненің хохыйы полды!

Ах хуус хуявының ізебінең

Хан Мирген пирген

Ырах кӧрченц кӥн кӧстікті

Сыварып алван.

Ах пайзаџз ибден сыzып киліп,

Азахти тастап кӧрібіскен.

Ах пайзаң ибннің алнынаң

Хуу пӥӱрнец хара тӥлгӥнің

Ізі-чольн кӧріп тапхан.

Iстерін істеп,

Чолларын чоллап кӧр турчададыр.

Ыраххы чирге чітіре кӧр тур:

Чир чабызы чирде

Читіре ойлас парыбысххан

Хара тӥлгйнен

Хуу пӥурні коріп тапхан.

Хара савыстыз Хара Нинчінең

Чабал савыстыз Oчыс Capblz обладают способностью превращаться в лисиц и иных зверей и намеренно совершают злодеяния:

'[На] каменистый хребет забежали Три лисы с черно-серебристой шерстью. Завертевшись, встряхнулись Хара Нинчи [с] Пора Нинчи [И] Ӱзӱм Чачах превратились' [Курбижекова 2011: 97]; (перевод наш. - В. Б.);

'Хара Нинчи с Очы-Сарыг тогда

[Из] белого дворца вышли:

„Ну, сейчас Албынчы будет

горевать“", - [злорадно] говорят, Черной лисицей обратившись,

Хара Нинчи,

Белесым волком ставшая

Очы Сарыг,

В сторону захода солнца глядя,

Побежали'

[Албынчі 1951: 83]; (перевод наш. - В. Б.);

'Богатырка Хан Хыс сокрушается:

- Отцово горе случилось,

- Матери отчаянье настало!

Из кармана белого кожаного доспеха

[От] Хана Миргена полученное,

Далеко [всё] видящее солнцу

[подобное] зеркало

Достала.

[Из] белого дворца выйдя,

[В] ноги бросив, взглянула.

[И] перед белым дворцом

Белесого волка [и] черной лисицы

Следы-дорожку обнаружила.

Следы распутывая,

[И] дорожку исследуя, глядит.

[Вплоть до] дальней земли обозревает:

[До самых] низин земли

Достигших, стремглав убегающих

Черную лисицу

[И] белесого волка узрела.

[C] черными мыслями Хара Нинчи

[C] дурными мыслями Очы Сарыг 
Чир чабызы чирге чит парыбысханнар. Ікі палазы оларның хольна Тёс парван парчададыр.
Низин подземелья достигли

Двое детей [её] в их руки

Попавши, [с ними] идут'

[Ай Хуучын 1958: 361-362]; (перевод наш. - В. Б.).
В мировоззрении хакасов Нижний мир, как правило, отождествляется с пространством, в котором отсутствует свет и царит вечная тьма. Поэтому в устном народном творчестве по отношению к нему обычно применяется эпитет хара — 'чёрный' или xan-xapa / xan-xapacxa 'чёрный-пречёрный / промозглая тьма'. Совершенно естественно и то, что жители подземного царства также обладают соответствующей номинацией - харалар/харазы. Поэтому не случаен тот факт, что масть лисиц, обитающих там, имеет соответствующую колоративную характеристику. В связи с этим богатыри представители светлого, солнечного мира для того, чтобы беспрепятственно попасть туда, нередко оборачиваются в черных лисиц [Алтын Арыг 1988: 545].

В богатырских сказаниях встречается сюжет, связанный с непосредственной расправой героя с нечистой силой, представленной в виде черной лисицы. В финале этого действа, когда спадают ее чары, она проявляет свой изначальный женский образ:
Альп тӧреен чалаас оолах амды Ат чобатхан хара тӥлгӥзін

Паарынаң айланза, паарынаң саапча. Арвазынан айланза, арвазынаң саапча. Хатыз совыс полван туста Хырых хулас сынныг ол тӥлгё Аар-пеер айланган - сах-андох $\ddot{Y}_{с}$ азыр хара чылан сёрместіг Ӱчен-Арыг хыс абахай пол-парван Ўчен-Арывны чалаас оолах Хап чілеп аар-пеер сӧзір-тур, Теер чілеп аны истеп-тур. $\ddot{Y}$ деe, ac maa aнbl cannadbl, ӱзілбес тынын ӥзе сапты
'Богатырем рожденный, голый мальчик теперь [На] лошади [своей] до измождения [преследованием] черной лисицы

[Ту лисицу] печенью повернув, по печени бьет. Спиной развернув, по хребту бьет.

Во время жестокой расправы

О сорока саженей та лисица

Туда-сюда извивалась - и там же

[C] тремя растопыренными змеевидными косичками

[B] Учен Арыг деву-красавицу превратилась

Учен Арыг [деву] голый мальчик,

Подобно мешку, туда-сюда волочит,

Подобно шкуре, ее выделывает.

[И] не долго, [и] немного ее бил.

Необрываемую душу-дыхание [еe] ударом оборвал'

[Кильчичаков 1946: 84-85]; (перевод наш. - В. Б.).
Вера хакасов в то, что лисица непосредственно связана с Нижним миром и нечистой силой, а значит, потенциально опасна и вредоносна, нашла отражение в дорожных приметах. Считалось неблагоприятным знаком, когда лисица перебегала путнику дорогу. Отметим, что подобные представления были распространены и среди монгольских народов [Содномпилова 2009: 323]. Помимо того, хакасские охотники были убеждены в том, что если в процессе охоты первой из зверей попадалась лисица и если они ее не сумели подстрелить, то промысел будет заведомо неудачным. В таком случае охотники сразу же покидали промысловые угодья и возвращались домой [Карачаков 2004: 63].

\section{Заключение}

Исходя из изложенного материала, можно сделать вывод о том, что лисица занимала важное место в культуре хакасов. На протяжении веков она была и остается одним из распространенных и ценных промысловых зверей. Лисий мех, обладая высокой материальной и символической ценностью, был чрезвычайно востребован у населения и был одним из распространенных предметов торгового обмена, выполняя функцию платежного средства.

Лисьи шкуры широко использовались хакасами при изготовлении головных уборов и шуб. Наиболее известным и высоко значимым предметом гардероба являлась лисья шапка свахи - тӥлгё пӧрік. Ее образ 
был широко запечатлен в фольклоре и обрядовой практике народа. Заметим, что на фотографиях хакасов, запечатленных в конце XIX - начале XX столетия, довольно часто встречаются женщины в костюме свахи и с лисьей шапкой на голове.

В традиционном мировоззрении хакасов образ лисицы сложен и неоднозначен. В процессе формирования характерных черт мифологического образа этого зверя повлияла сама ее биологическая природа, главным образом, ее внешние данные, поведение и среда обитания. В мифологическом мышлении проекция ее зоологических особенностей выразилась в наделении ее образа такими чертами, как высокий интеллектуальный потенциал, прекрасное чутье, проворство и высокая мобильность. Мифологический облик лисицы связан с представлением о небе и небесных объектах и вместе с тем имеет прямое отношение к нижним сферам мироздания и ее демоническим обитателям.

\section{Литература}

Ай Мічікнің 1993 - Ай Мічікнің и Кӱн Мічік // Ай Мичик и Кюн Мичик. Богатырские сказания. Абакан: Хак. кн. изд-во, 1993. С. 4-62.

Ай Хуучын 1958 - Ай Хуучын // Алтын Арығ. Алыптығ нымах (Героическое сказание). Абакан: Хак. кн. изд-во, 1958. С. 318-419.

Албынчі 1951 - Албынчі // Алыптығ нымахтар (Героические сказания). Абакан: Хак. обл. кн. изд-во, 1951. С. 13-98.

Алексеев 1975 - Алексеев Н. А. Традиционные религиозные верования якутов в XIX - начале XX в. Новосибирск: Наука, 1975. 188 с.

Алтын Арыг 1988 - Алтын Арыг. Хакасский героический эпос. М.: Наука, 1988. 592 с.

Алтын Тайчы 1973 - Алтын Тайчы. Алыптығ нымах (Героическое сказание). Абакан: ХO Красноярск. кн. изд-ва, 1973. 148 с.

Бурнаков 2016 - Бурнаков В. А. Зооморфные фетиши - тӧс'ы в традиционной обрядовой практике хакасов (конец XIX - середина XX в.) // Религиоведение. 2016. № 1. С. 3146.

Бутанаев 2003 - Бутанаев В. Я. Бурханизм тюрков Саяно-Алтая. Абакан: Изд-во ХГУ, 2003. $260 \mathrm{c}$.

Бутанаев, Монгуш 2005 - Бутанаев В. Я., Монгуш Ч. В. Архаические обычаи и обряды саянских тюрков. Абакан: Изд-во ХГУ, 2005. $200 \mathrm{c}$.

Бутанаев 2006 - Бутанаев В. Я. Традиционный шаманизм Хонгорая. Абакан: Изд-во ХГУ, 2006. $254 \mathrm{c}$.
Лисица наделялась чертами медиатора, беспрепятственно преодолевающего огромные пространства и курсирующего между мирами. Подобное ее восприятие способствовало включению лисицы в шаманскую практику и традиционную обрядность хакасов. Она была включена в круг представлений, связанных с домашними духами-покровителями, и была задействована в народной медицине и бытовой магии.

Одной из ключевых особенностей восприятия лисицы было ее отождествление с женским началом. При этом согласно устному народному творчеству хакасов в образе этого зверя могли воплощаться как положительные, так и отрицательные героини.

Все вышеприведенное свидетельствует о том, что образ лисицы в мировоззрении хакасов обладал широким семантическим полем, в котором совмещались полярные черты и признаки.

Вербицкий 1993 - Вербицякий В. И. Алтайские инородцы. Горно-Алтайск: Ак Чечек, 1993. $270 \mathrm{c}$.

Герасимов 1950 - Герасимов Ю. А. Лисица. М.: Заготиздат, 1950. $71 \mathrm{c.}$

Доможаков 1951 - Доможаков В. И. Хакасские загадки // Записки ХакНИИЯЛИ. Вып. 2. Абакан: Хак. обл. гос. изд-во, 1951. С. 60-84.

Зворыкин 1929 - Зворыкин Н. А. Охота на лисиц. М.: Изд-ие Всекохотсоюза, 1929.75 с.

Карачаков 2004 - Карачаков C. E. Чоныма ӧдізім айландарчам (= Возвращаю свой долг народу). Абакан: Хак. кн. изд-во, 2004. 112 с.

Катанов 1887 - Катанов Н. Ф. Сказания и легенды минусинских татар // Сибирский сборник. 1887. Т. XXV. С. 218-235.

Катанов 1907 - Катанов Н. Ф. Наречия урянхайцев (сойотов), абаканских татар и карагасов: (Образцы народной литературы тюркских племен, изданные В. В. Радловым). СПб.: [б. и.],1907. Т. 9. 640 с.

Кильчичаков 1946 - Кильчичаков М. Е. Пили ала хара чабагалыг Пил Тарааннаңар // Хакасский фольклор. Абакан: Хакоблнациздат, 1946. С. 73-102.

Кӧк Хан 1974 - Кӧк Хан. Алыптығ нымах (На хак. яз.). Абакан: ХО Красноярск. кн. изд-ва, 1974. $112 \mathrm{c}$.

Костров 1884 - Костров Н. А. Очерки быта минусинских татар // Труды IV археологического съезда. Т. 1. Казань: Тип. Имп. ун-та, 1884. С. 208-248. 
Кропоткин 1895 - Кропоткин А. Саянский хребет и Минусинский округ // Живописная Россия. Т. ХІІ. Ч. 1. Восточные окраины России. Восточная Сибирь. СПб.; М.: Издие тов-ва М. О. Вольфа, 1895. С. 19-50.

Кузнецова, Кулаков 1898 - Кузнечова A. A., Кулаков П. Е. Минусинские и ачинские инородцы. Красноярск: Тип. Енис. губ. упр-я, 1898. 299 c.

Курбижекова 2011 - Курбижекова А. В. Сибен Арыг (героическое сказание). На хак. яз. Абакан: Хак. кн. изд-во, 2011. 324 с.

Лосев 2007 - Лосев С. О. Лисица и охота на нее. М.: Вече, 2007. 304 c.

Миллер 2009 - Миллер Г. Ф. Описание сибирских народов. М.: Памятники исторической мысли, 2009. 456 с.

Мифы 2006 - Мифы и легенды хакасов. Абакан: Хак. кн. изд-во, 2006. 210 с.

Мудрое слово 1976 - Мудрое слово. Сборник хакасских народных пословиц и поговорок и загадок. Абакан: ХО Красноярск. кн. издва, 1976.128 с

Николаева 2010 - Николаева Н. Н. Лиса в эпическом фольклоре бурят // Вестник Бурятского государственного университета. 2010. № 10. C. 277-283.

Овичев 1905 - Овичев. Богатырские поэмы Минусинских татар // Сибирский наблюдатель, 1905. Томск. Кн. 3 (март). С. 1-9.

Орфеев 1887 - Орфеев Н. Место обитания душ умерших людей - подземное царство, духи, управляющие им, и наказания грешников, по сказаниям минусинских инородцев (Материалы для изучения инородческих вероучений) // Енисейские епархиальные ведомости, 1887. № 15-16. С. 175-181.

Островских 1895 - Островских П. Е. Этнографические заметки о тюрках Минусинского края // Живая старина. 1895. Вып. 3-4. C. $297-348$

Попов 1884 - Попов Н. А. Поверья и некоторые обычаи качинских татар // Известия Императорского русского географического общества. Т. 20. Вып. 6. СПб., 1884. С. 645-659.

Потанин 2005 - Потанин Г. Н. Очерки Северо-Западной Монголии. Изд. 2-е. Горно-Алтайск: Ак Чечек, 2005. 1026 с.

Потапов 1952 - Потапов Л. П. Краткие очерки истории и этнографии хакасов (XVII-XIX вв.). Абакан: Хакоблгосиздат, 1952. 217 с.

Сагайский обряд 1998 - Сагайский обряд снятия порчи и очищения Т. С. Бурнаковой [электронный ресурс] // Культура РФ. Окказиональные обряды и магические практики https://www.culture.ru/objects/451/sagaiskiiobryad-snyatiya-porchi-i-ochisheniya-t-sburnakovoi (дата обращения: 21.12.2019).
Содномпилова 2009 - Содномпилова М. М. Мир в традиционном мировоззрении и практической деятельности монгольских народов. Улан-Удэ: Изд-во БНЦ СО РАН, 2009. 366 с. Содномпилова, Нанзатов 2016 - Содномпилова М. М., Нанзатов Б. 3. Зооморфный код в контексте этногенетических связей: Лиса в традиционных представлениях монгольских народов // Известия Иркутского государственного университета. Серия «Геоархеология. Этнология. Антропология». 2016. T. 15. C. $48-63$.

Субракова 2007 - Субракова О. В. Язык хакасского героического эпоса. Абакан: Хак. кн. изд-во, 2007. 164 с.

Сугробова 2004 - Сугробова В. Ю. Лиса и охота на нее. М.: ООО «Аквариум-Принт», 2004. $61 \mathrm{c}$

Тӱлгё-хызыл 1951 - Тӱлгё-хызыл Алып-хыс (= Красная Лисица Богатырша-дева') // Алыптығ нымыхтар (Героические сказания). Абакан: Хак. обл. изд-во, 1951. С. 101-156.

Унгвицкая, Майногашева 1972 - Унгвицкая M. A., Майногашева В. Е. Хакасское народное поэтическое творчество. Абакан: ХО Красноярск. кн. изд-ва, 1972. 312 с.

Хакасские... 1980 - Хакасские народные тахпахи. Абакан: Хак. кн. изд-во, 1980. 132 с.

Хакасский героический 1997 - Хакасский героический эпос: Ай-Хуучин. Новосибирск: Наука, 1997. 479 с.

Хан Орба 1989 - Хан Орба: Богатырское сказание, записанное от С. И. Шулбаева (на хак. яз.). Абакан: Хак. издат., 1989. 208 с.

Хан-Тонис 2007 - Хан-Тонис на темно-сивом коне. Богатырское сказание М. Р. Баинова. Новосибирск: Новосибирск. кн. изд-во, 2007. $384 \mathrm{c}$

Хара Хусхун 1977 - Хара Хусхун. Алыптығ нымах (= Героическое сказание). Абакан: ХО Красноярск. кн. изд-ва, 1977. 196 с.

Чудновский 1885 - Чудновский $С$. Л. Енисейская губерния: $\mathrm{K}$ трехсотлетнему юбилею Сибири (Статистико-публицистические этюды). Томск: Тип-я «Сибирской газеты», $1885.198 \mathrm{c}$

Шибаева 1959 - Шибаева Ю. А. Одежда хакасов. Сталинабад: Таджикский гос. ун-т им. В. И. Ленина, 1959. 126 с.

Шулбаева 2016 - Шулбаева Н. В. Образы женщин-богатырок в героическом эпосе хакасов как символ национальной гордости // Научное обозрение Саяно-Алтая. 2016. № 2 (14). C. 89-92.

Щукин 1847 - Щукин Н. С. Звериные промыслы в Восточной Сибири // Журнал Министерства внутренних дел. 1847. Ч. 19. C. $408-446$. 


\section{References}

[Altyn Aryg: a Khakas Heroic Epic]. Moscow: Nauka, 1988. 592 p. (In Khak.)

[Altyn Taichy: a Heroic Tale]. Abakan: Khakas Branch of Krasnoyarsk Book Publ., 1973. 148 p. (In Khak.)

[Ay-Khuuchin: a Khakas Heroic Epic]. Novosibirsk: Nauka, 1997. 479 p. (In Russ.)

[Khakas Folk Takhpakhs]. Abakan: Khakas Book Publ., 1980. 132 p. (In Russ. and Khak.)

[Khakas Myths and Legends]. Abakan: Khakas Book Publ., 2006. 210 p. (In Russ.)

[Khan Orba: a Heroic Tale Recorded from S. I. Shulbaev]. Abakan: Khakas Book Publ., 1989. 208 p. (In Khak.)

[Khan-Tonis Riding the Dark Grey Horse: a Heroic Tale Recorded from M. R. Bainov]. Novosibirsk: Novosibirsk Book Publ., 2007. 384 p. (In Russ.)

[Khara Khuskhun: a Heroic Tale]. Abakan: Khakas Branch of Krasnoyarsk Book Publ., 1977. 196 p. (In Khak.)

[Kök Khan: a Heroic Tale]. Abakan: Khakas Branch of Krasnoyarsk Book Publ., 1974. 112 p. (In Khak.)

[The Word of Wisdom: Collected Khakas Proverbs, Sayings, and Riddles]. Abakan: Khakas Branch of Krasnoyarsk Book Publ., 1976. 128 p. (In Russ.)

Albynchi. In: [Heroic Tales]. Abakan: Khakas Oblast Book Publ., 1951. Pp. 13-98. (In Khak.)

Alekseev N. A. [Traditional Religious Beliefs of the Sakha: $19^{\text {th }}-$ Early $20^{\text {th }}$ Centuries]. Novosibirsk: Nauka, 1975. 188 p. (In Russ.)

Ay Khuuchyn. In: [Altyn Aryg: a Heroic Tale]. Abakan: Khakas Book Publ., 1958. Pp. 318419. (In Khak.)

Ay Michiknin and Kün Michik. In: [Ay Michik and Kün Michik: Heroic Tales]. Abakan: Khakas Book Publ., 1993. Pp. 4-62. (In Khak.)

Burnakov V. A. Tös zoomorphic fetishes in Khakas traditional rites: late $19^{\text {th }}-$ mid- $20^{\text {th }}$ centuries. $R e$ ligiovedenie. 2016. No. 1. Pp. 31-46. (In Russ.)

Butanaev V. Ya. [Burkhanism of Sayan-Altai Turks]. Abakan: Khakas State University, 2003. 260 p. (In Russ.)

Butanaev V. Ya. [Traditional Shamanism of Khongorai]. Abakan: Khakas State University, 2006. $254 \mathrm{~s}$.

Butanaev V. Ya., Mongush Ch. V. [Sayan Turks: Archaic Customs and Rites]. Abakan: Khakas State University, 2005. 200 p. (In Russ.)

Chudnovsky S. L. [Yeniseysk Governorate: Statistical and Journalistic Sketches. Celebrating the Tercentenary of Russian Siberia]. Tomsk: Sibirskaya Gazeta, 1885. 198 p. (In Russ.)
Domozhakov V. I. Khakas riddles. In: [Khakas Research Institute of Language, Literature and History: (Scholarly) Notes]. Vol. 2. Abakan: Khakas Oblast State Publ., 1951. Pp. 60-84. (In Russ.)

Gerasimov Yu. A. [Fox]. Moscow: Zagotizdat, 1950. 71 p. (In Russ.)

Karachakov S. E. [Repaying Debts to the People]. Abakan: Khakas Book Publ., 2004. 112 p. (In Khak.)

Katanov N. F. [Dialects of the Uriankhai (Soyots), Abakan Tatars, and Karagases: Examples of Turkic Folk Literature Published by V. V. Radlov]. St. Petersburg, 1907. Vol. 9. 640 p. (In Russ.)

Katanov N. F. Tales and legends of Minusinsk Tatars. Sibirskiy sbornik. 1887. Vol. XXV. Pp. 218-235. (In Russ.)

Kilchichakov M. E. Heroic Tale of Pil Taraan. In: [Khakas Folklore]. Abakan: Khakas Oblast National Publ., 1946. Pp. 73-102. (In Khak.)

Kostrov N. A. Minusinsk Tatars: Sketches of Everyday Life. In: [ $4^{\text {th }}$ Archaeological Congress]. Proc. Kazan: Imperial Kazan University, 1884. Vol. 1. Pp. 208-248. (In Russ.)

Kropotkin A. The Sayan and Minusinsk District. In: [Picturesque Russia]. Vol. XII. Part 1: Russia's East. Eastern Siberia. St. Petersburg; Moscow: M. O. Wolf, 1895. Pp. 19-50. (In Russ.)

KULTURA.RF (culture.ru). Sagay anti-sorcery and cleansing rites by T. S. Burnakova. Occasional rites and magic practices. Available at: https:// www.culture.ru/objects/451/sagaiskii-obryad-snyatiya-porchi-i-ochisheniya-t-s-burnakovoi (accessed: December 21, 2019). (In Russ.)

Kurbizhekova A. V. [Siben Aryg: a Heroic Tale]. Abakan: Khakas Book Publ., 2011. 324 p. (In Khak.)

Kuznetsova A. A., Kulakov P. E. [Non-Russian Populations of Minusinsk and Achinsk Districts]. Krasnoyarsk: Yeniseysk Provincial Government, 1898. 299 p. (In Russ.)

Losev S. O. [Fox and Fox Hunting]. Moscow: Veche, 2007. 304 p. (In Russ.)

Müller G. F. [Description of Siberian Peoples]. Moscow: Pamyatniki Istoricheskoy Mysli, 2009. 456 p. (In Russ.)

Nikolaeva N. N. Fox in Buryat epic folklore. Buryat State University Bulletin. 2010. No. 10. Pp. 277-283. (In Russ.)

Orfeev N. Where souls of the dead live - the underworld, its ruling spirits, and punishment of the unrighteous: research materials on non-Russian beliefs and religions. Eniseyskie eparkhial'nye vedomosti. 1887. No. 15-16. Pp. 175-181. (In Russ.) 
Ostrovskikh P. E. Turks of Minusinsk District: ethnographic notes. Zhivaya starina. 1895. No. 3-4. Pp. 297-348. (In Russ.)

Ovichev. Heroic poems of Minusinsk Tatars. Sibirskiy nablyudatel'. 1905. Vol. 3 (March). Pp. 1-9. (In Russ.)

Popov N. A. Kacha Tatars: beliefs and some rites revisited. Izvestiya Imperatorskogo russkogo geograficheskogo obshchestva. 1884. Vol. 20. No. Pp. 645-659. (In Russ.)

Potanin G. N. [Essays on Northwestern Mongolia]. $2^{\text {nd }}$ ed. Gorno-Altaysk: Ak Chechek, 2005. 1026 p. (In Russ.)

Potapov L. P. [History and Ethnography of the Khakas People, $17^{\text {th }}-19^{\text {th }}$ Centuries: Brief Essays]. Abakan: Khakas Oblast State Publ., 1952. 217 p. (In Russ.)

Shchukin N. S. Fur hunting and trapping in Eastern Siberia. Zhurnal Ministerstva vnutrennikh del. 1847. Vol. 19. Pp. 408-446. (In Russ.)

Shibaeva Yu. A. [Khakas Garments]. Stalinabad: Lenin Tajik State University, 1959. 126 p. (In Russ.)

Shulbaeva N. V. Images of women-heroes in the heroic epos of the Khakass as a symbol of national pride. Sayan-Altai Scientific Review. 2016. No. 2 (14). Pp. 89-92. (In Russ.)
Sodnompilova M. M. [Mongolic Peoples: the World in Traditional Worldviews and Practical Activities]. Ulan-Ude: Buryat Scientific Center (Sib. Branch) of RAS, 2009. 366 p. (In Russ.)

Sodnompilova M. M., Nanzatov B. Z. Zoomorphic code in ethnogenetic context: fox in traditional beliefs of Mongolian peoples. Bulletin of the Irkutsk State University. Geoarchaeology, Ethnology, and Anthropology Series. 2016. Vol. 15. Pp. 48-63. (In Russ.)

Subrakova O. V. [Language of Khakas Heroic Epic]. Abakan: Khakas Book Publ., 2007. 164 p. (In Russ.)

Sugrobova V. Yu. [Fox and Fox Hunting]. Moscow: Akvarium-Print, 2004. 61 p. (In Russ.)

The Red Fox Female Hero. In: [Heroic Tales]. Abakan: Khakas Oblast Publ., 1951. Pp. 101156. (In Khak.)

Ungvitskaya M. A., Maynogasheva V. E. [Khakas Folk Poetry]. Abakan: Khakas Branch of Krasnoyarsk Book Publ., 1972. 312 p. (In Russ.)

Verbitsky V. I. [Non-Russian Populations of the Altai Mountains]. Gorno-Altaysk: Ak Chechek, 1993. 270 p. (In Russ.)

Zvorykin N. A. [Fox Hunting]. Moscow: All-Union Cooperative Hunting Association, 1929. 75 p. (In Russ.) 